It is only prudent that gatherers know thoroughly the poisonous plants they might encounter. They could well invest in such books as: Common Poisonous Plants of the Northern Plains Dangerous to Man by L.J. Schermeister (N. Dak. State Univ., \$1.10, paper), Poisonous Plants of the United States by W.C. Muenscher (Collier, \$5.50, 1939), and Deadly Harvest by J.M. Kingsbury (Holt, Rinehart \& Winston, \$2.35, paper). These are three books dealing with this important topic. The literature on edible and poisonous fungi is a separate study in itself.

Please note that the prices I have quoted above are the list prices of books still in stock. Replacement supplies could well cost more. However, at any price, books on wild edible plants are worthwhile investments which could well open the door to a new and exciting experience. Incidentally, The BLUE JAY
BOOKSHOP would be glad to report availability and price of any title for any member of SNHS on request. Simply drop us a line at P.O. Box 1121, Regina, Sask. S4P 3B4.

\section{SNHS SPECIAL PUBLICATIONS -} STANDING ORDERS

The BLUE JAY BOOKSHOP maintains a Standing Order List for SNHS Special Publications. We urge members to put their names on this S.O. List so that each Special Publication, with invoice, will be sent automatically. No waiting! Avoid disappointment! Send your name and mailing address to: The BLUE JAY BOOKSHOP, P.O. Box 1121, Regina, Sask. S4P 3B4.

In press BELCHER, M.: THE BIRDS OF REGINA (REVISED). Several more due soon! Get them as they are published!

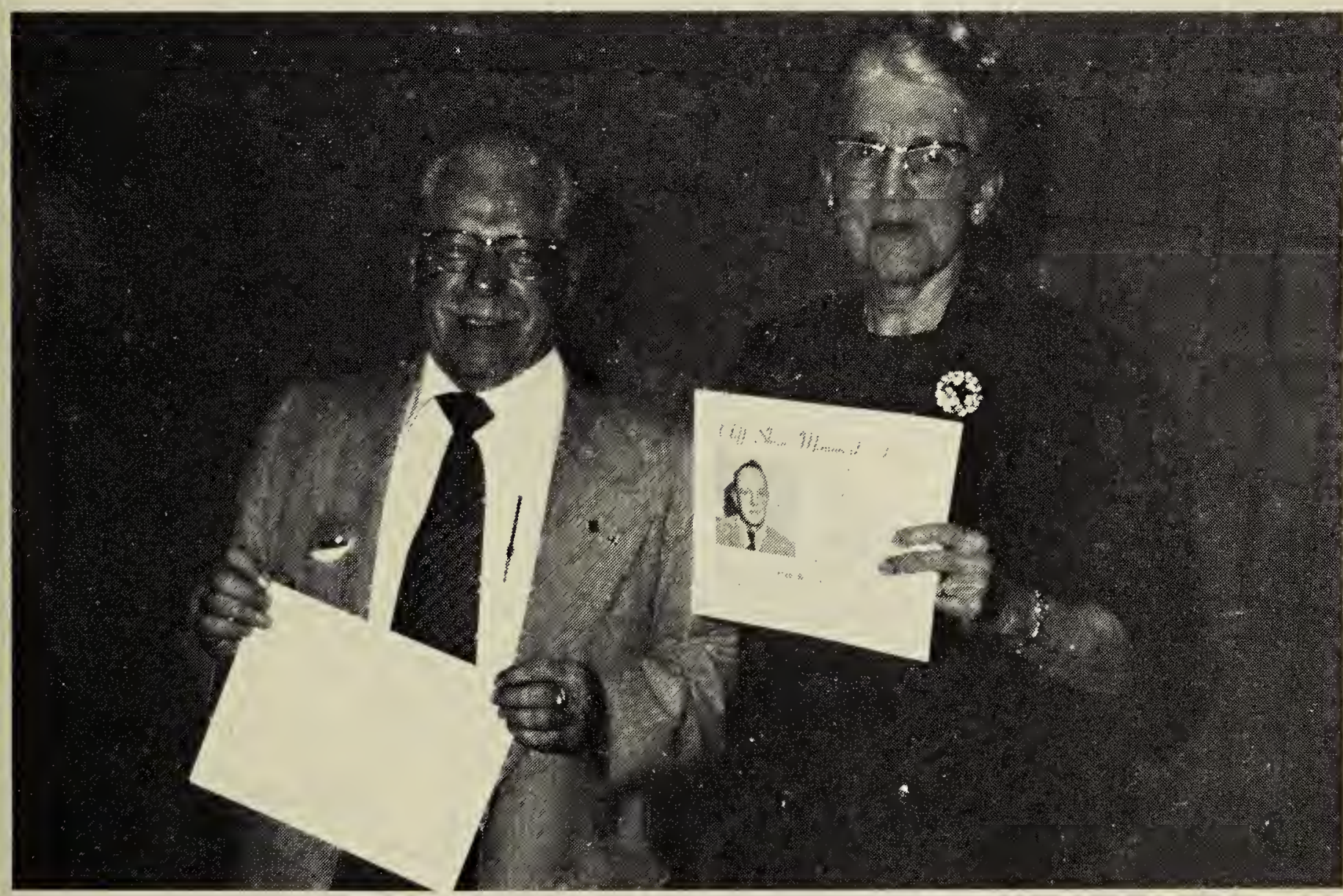

1979 AWARD WINNERS: Frank Brazier, who was presented the Conservation Award for his long service to the Society, and the management of the Blue Jay Bookshop, poses with Jean Bancroft of Winnipeg, who was presented the Cliff Shaw Award for a series of articles on bird nesting behavior.

Gary W. Seib 